Article

\title{
Association between Objectively Measured Sedentary Behaviour and Sleep Quality in Japanese Adults: A Population-Based Cross-Sectional Study
}

Keita Kinoshita ${ }^{1,2,3} \mathbb{D}$, Naoki Ozato ${ }^{1,2} \mathbb{D}^{\mathbb{D}}$, Tohru Yamaguchi ${ }^{2} \mathbb{D}$, Motoki Sudo ${ }^{4}$, Yukari Yamashiro ${ }^{4}$, Kenta Mori ${ }^{1,2}$, Yoshihisa Katsuragi ${ }^{1,2}$, Takuji Yasukawa ${ }^{1}$, Koichi Murashita ${ }^{5}$, Shigeyuki Nakaji ${ }^{3}$ (D) and Kazushige Ihara ${ }^{3, *}$

1 Department of Active Life Promotion Sciences, Graduate School of Medicine, Hirosaki University, Hirosaki City 036-8562, Japan; kinoshita.keita@kao.com (K.K.); oozato.naoki@kao.com (N.O.); mori.kenta@kao.com (K.M.); katsuragi.yoshihisa@kao.com (Y.K.); takuji.yasukawa@hirosaki-u.ac.jp (T.Y.)

2 Health \& Wellness Products Research Laboratories, Kao Corporation, Tokyo 131-8501, Japan; yamaguchi.tohru@kao.com

3 Department of Social Medicine, Graduate School of Medicine, Hirosaki University, Hirosaki City 036-8562, Japan; nakaji@hirosaki-u.ac.jp

4 Personal Health Care Products Research Laboratories, Kao Corporation, Tokyo 131-8501, Japan; sudou.motoki@kao.com (M.S.); yamashiro.yukari@kao.com (Y.Y.)

5 COI Research Initiatives Organization, Graduate School of Medicine, Hirosaki University, Hirosaki City 036-8562, Japan; murasita@hirosaki-u.ac.jp

check for updates

Citation: Kinoshita, K.; Ozato, N.; Yamaguchi, T.; Sudo, M.; Yamashiro, Y.; Mori, K.; Katsuragi, Y.; Yasukawa, T.; Murashita, K.; Nakaji, S.; et al. Association between Objectively Measured Sedentary Behaviour and Sleep Quality in Japanese Adults: A Population-Based Cross-Sectional Study. Int. J. Environ. Res. Public Health 2022, 19, 3145.

https://doi.org/10.3390/ ijerph19053145

Academic Editors:

Francesco Fischetti and

Stefania Cataldi

Received: 20 January 2022

Accepted: 3 March 2022

Published: 7 March 2022

Publisher's Note: MDPI stays neutral with regard to jurisdictional claims in published maps and institutional affiliations.

Copyright: (C) 2022 by the authors. Licensee MDPI, Basel, Switzerland. This article is an open access article distributed under the terms and conditions of the Creative Commons Attribution (CC BY) license (https:// creativecommons.org/licenses/by/ $4.0 /)$.
* Correspondence: ihara@hirosaki-u.ac.jp; Tel.: +81-172-39-5041; Fax: +81-172-39-5038

\begin{abstract}
The association between sedentary behaviour and sleep quality (SQ) remains unclear, partly due to the limited methodology for assessing sedentary time and the influence of obesity. This study aimed to examine the association between objectively measured sedentary time and poor SQ, as well as the association of visceral fat accumulation. This cross-sectional study used health check-up data obtained from 721 Japanese adults. Sedentary time and physical activity were measured using an accelerometer for $\geq 7$ days, with $\geq 10$ measurement hours per day. Poor SQ was determined by a Pittsburgh Sleep Quality Index score of $\geq 6$. Visceral fat was measured using the abdominal bioimpedance method. A logistic regression model was used to analyse the association between sedentary time and SQ. We found that higher sedentary time was associated with poorer SQ. This association remained significant after adjustment for several covariates, including visceral fat. Compared with the lowest tertile of sedentary time, the second and highest tertile had a significantly higher OR of poor SQ (Tertile 2: OR = 2.06 [95\% CI 1.14,3,73]; Tertile 3: OR = 2.76 [95\% CI 1.49, 5.11]). These results suggest that managing sedentary time itself might contribute to improving SQ.
\end{abstract}

Keywords: physical activity; sedentary behaviour; sleep quality; intra-abdominal fat

\section{Introduction}

Sleep problems constitute a global epidemic that threatens health and quality of life (QOL), with a prevalence of up to 56\% worldwide [1-3]. Sleep quality (SQ), the subjective assessment of sleep, is associated with several health outcomes, such as brain health, cardiovascular health, metabolic health, and mortality [4]. A recent study in Japan demonstrated that poor SQ was observed in $16 \%$ of people over a wide age range and was associated with poor QOL [5]. Although hypnotic medications are widely used to promote good SQ, a free or low-cost method with a low risk of adverse side effects is needed for health promotion of the population.

Engaging in physical activity is a non-pharmacological method for increasing SQ. Greater amount of moderate-to-vigorous physical activity (MVPA) is associated with significantly better SQ and reduced frequency of sleep medication [6]. In 2020, the World Health Organization (WHO) guidelines on physical activity and sedentary behaviour 
recommended physical activity to improve sleep outcomes [7]. The guidelines also emphasised the association between sedentary behaviour and sleep; however, evidence for this was mainly focused on children and adolescents. Evidence for the relationship between sedentary behaviour and SQ in adults is inconsistent [8-11], partly due to the limited number of studies, differences in sample size, relatively narrow age range, differences in sedentary time according to race/ethnicity [12], physical activity level, and limited methodology. Additionally, most of these studies have assessed physical activity subjectively instead of using objective methods such as accelerometery, which is currently regarded as the gold standard [13]. Therefore, evidence is still needed regarding the association between objectively measured sedentary behaviour and SQ.

Sedentary behaviour is associated with obesity, and obesity is reportedly associated with sleep disturbance [14]. Previous studies have analysed the association between sedentary behaviour and SQ by adjusting body mass index (BMI), considering it as a modifier for the aforementioned association. Furthermore, the Asian population has a higher susceptibility to visceral fat accumulation, which is cause of metabolic syndrome [15], and visceral fat area (VFA) as one of the indexes of obesity is more strongly associated with sleep disturbance than BMI [16]. However, no studies have considered visceral fat to examine the association between sedentary behaviour and SQ, even in Asian populations.

Therefore, the aim of this study was to examine the association between objectively measured sedentary time and SQ, considering the association of VFA in Japanese adults.

\section{Materials and Methods}

\subsection{Study Design and Participants}

The Iwaki Health Promotion Project was launched in 2005. As part of the activities of the project, an annual health check-up was conducted for adults living in the Iwaki region of Hirosaki city, Aomori prefecture, located in northern Japan [17]. All adult residents $(\approx 10,000)$ of this region were invited to participate based on resident registration, resulting in approximately $10 \%$ of the adult residents voluntarily participating. This population-based cross-sectional study analysed data obtained from the health checkup conducted from late May to early June in 2018 on 1056 individuals. This study was approved by the Ethics Committee of Hirosaki University School of Medicine (2018-012, 2018-063) and conducted in accordance with the principles of the Declaration of Helsinki. All study participants provided written informed consent. This study was registered with the University Hospital Medical Information Network (UMIN-CTR, https: / / www.umin. ac.jp, UMIN ID: UMIN000036741, accessed on 5 January 2022).

\subsection{Measurements of Sedentary Time and Physical Activity}

Sedentary time and physical activity were measured using an accelerometer (HW100, Kao Corporation, Tokyo, Japan), which allowed 40 days of continuous recording at a sampling frequency of $64 \mathrm{~Hz}$. The epoch length of the accelerometer was $4 \mathrm{~s}$. The activity intensity was measured as previously described [18-20]. Briefly, accelerometer data were calculated as the time spent in each of the following three intensity levels: sedentary behaviour, $\leq 1.5$ metabolic equivalent tasks (METs), and MVPA, $\geq 3$ METs. A period of $\geq 35 \mathrm{~min}$, where activity was not recorded using an accelerometer, was defined as the non-wear time. Sedentary time and MVPA were expressed as the mean daily hours across all adherent days (wear time $\geq 10 \mathrm{~h}$ /day) for all the participants.

The participants were instructed to wear the HW-100 on their waist throughout their awake period, while maintaining their daily activities, except during swimming or bathing. Additionally, the participants were instructed to begin wearing the HW-100 promptly after completing their health check-up and to return it after 10 days. The criterion for analysis was wearing the accelerometer for a total duration of $\geq 7$ days ( $\geq 10 \mathrm{~h} /$ day) within the first 10 days after starting to wear the accelerometer. 


\subsection{Pittsburgh Sleep Quality Index (PSQI)}

The Japanese version of the PSQI [21], validated using a control group among Japanese individuals with psychiatric disorders, was used to assess the SQ of the participants over the past month. The PSQI contains 19 self-rated questions aggregated into seven component scores (range of subscale scores, 0-3): sleep quality, sleep latency, sleep duration, habitual sleep efficiency, sleep disturbance, use of sleeping medication, and daytime dysfunction. The sum of these seven component scores yields a global score (range 0-21), which indicates subjective SQ. Higher PSQI global scores indicate poorer SQ. Poor SQ was defined as a PSQI global score of $\geq 6$.

\subsection{Visceral Fat Measurement}

VFA was measured using a bioimpedance-type visceral fat meter (EW-FA90; Panasonic Corporation, Osaka, Japan), which is a certified medical device in Japan (No. 22500BZX005 22000) for non-invasive VFA measurement [22]. Measurements obtained using this device are strongly correlated with those obtained using computed tomography [23], which is the gold standard for VFA measurement.

\subsection{Other Variables}

We obtained data regarding smoking habits using self-administered questionnaires prepared for the annual health check-up. Daily alcohol intake was determined using the Brief Diet History questionnaire [24,25]. Alcohol intake was categorised as none, low intake $(<20 \mathrm{~g} /$ day), and high intake ( $\geq 20 \mathrm{~g} /$ day). Depressive status was assessed using the Centre for Epidemiologic Studies for Depression (CES-D) [26]. The questionnaire has been widely used to measure depressive symptoms in community populations and is also used as a screening tool for depression. Height, body weight, and BMI (calculated from height and body weight) were also measured.

\subsection{Statistical Analysis}

Given the strong correlation between accelerometer wear time and sedentary time $(\mathrm{r}=0.72)$, we standardised sedentary time to $16 \mathrm{~h} /$ day of accelerometer wear time using the residuals obtained when regressing sedentary time on accelerometer wear time as previously described [27-29]. The participants were categorized into tertile groups based on the standardised sedentary time as follows: Tertile 1: sedentary time $<10.4 \mathrm{~h}$; Tertile 2: $10.4 \mathrm{~h} \leq$ sedentary time $<11.5 \mathrm{~h}$; Tertile 3 : sedentary time $\geq 11.5 \mathrm{~h}$.

Participant characteristics are reported as median and interquartile range (IQR) or percentage. Continuous and categorical variables were compared between the two groups using Mann-Whitney U or Fisher's exact tests and tertile groups using the CochranArmitage trend test.

To evaluate the association between sedentary time and the seven component scores of the PSQI, we used Spearman's correlation coefficient. The method of Holm was applied to control the family-wise error rate in multiple comparisons. In addition, regression analysis with stepwise variable selection method was performed to investigate independent explanatory variables for the sedentary time.

Logistic regression analysis was used to determine the odds ratio (OR) and 95\% confidence interval (CI) for SQ quality, which compared participants in the lowest tertiles of sedentary time to those in the higher tertile. We assessed linear trends across tertiles by including each participant's tertile as an ordinal variable in the regression analysis. For the associations between VFA or BMI and poor sleep quality, the OR was represented per 1 standard deviation (SD) change in VFA or BMI.

Statistical tests were two-tailed, and statistical significance was set at $p<0.05$. As interactions by age and sex with sedentary behaviour were not statistically significant, pooled analyses were conducted. All analyses were performed using SPSS version 25 (SPSS Inc., Chicago, IL, USA) and the R environment (version 3.6.2; R Core Team, Vienna, Austria). 


\section{Results}

In 2018, 1056 individuals participated in the health check-up. A total of 178 participants with incomplete clinical assessments, dietary data, PSQI data, CES-D data, or accelerometer data were excluded. Additionally, 157 participants who did not meet the inclusion criteria for the accelerometer data were also excluded. Finally, this study included 721 participants (277 men and 444 women) aged $20-88$ years.

Among them, $13.5 \%$ reported PSQI $\geq 6$. Table 1 shows the characteristics of the participants classified by their PSQI. Participants who were PSQI $\geq 6$ were younger $(p=0.031)$, had higher CES-D scores $(p<0.001)$, higher sedentary time $(p<0.001)$, and were women $(p=0.052)$. Smoking status, alcohol intake, BMI, VFA, accelerometer wear time, and MVPA were not significantly different between the two groups.

Table 1. Participant characteristics classified by PSQI global score.

\begin{tabular}{|c|c|c|c|}
\hline & $\begin{array}{c}\text { PSQI }<6 \\
(n=599)\end{array}$ & $\begin{array}{c}\text { PSQI } \geq 6 \\
(n=122)\end{array}$ & $p$-Value \\
\hline Age, years & $58(44-66)$ & $52(39-65)$ & 0.031 \\
\hline Sex, \% women & 59.9 & 69.7 & 0.052 \\
\hline \multicolumn{4}{|l|}{ Smoking Status, \% } \\
\hline Never & 62.9 & 68.0 & 0.105 \\
\hline Former & 23.9 & 15.6 & \\
\hline Current & 13.2 & 16.4 & \\
\hline \multicolumn{4}{|l|}{ Alcohol intake, $\%$} \\
\hline None & 43.1 & 51.6 & 0.239 \\
\hline Low $(<20$ g/day $)$ & 34.6 & 29.5 & \\
\hline $\operatorname{High}(\geq 20 \mathrm{~g} /$ day $)$ & 22.4 & 18.9 & \\
\hline CES-D score & $5(2-10)$ & $12(6-20)$ & $<0.001$ \\
\hline BMI, $\mathrm{kg} / \mathrm{m}^{2}$ & $22.5(20.3-24.7)$ & $22.8(20.6-25.3)$ & 0.789 \\
\hline $\mathrm{VFA}, \mathrm{cm}^{2}$ & $75(48-108)$ & $79(50-111)$ & 0.774 \\
\hline Accelerometer wear time, $\mathrm{h} /$ day & $15.5(14.2-16.6)$ & $15.6(14.4-17.2)$ & 0.341 \\
\hline Sedentary time, $\mathrm{h} /$ day $^{1}$ & $10.9(9.87-11.8)$ & $11.4(10.6-12.2)$ & $<0.001$ \\
\hline MVPA, h/day & $0.38(0.26-0.53)$ & $0.39(0.27-0.53)$ & 0.616 \\
\hline PSQI global score & $3(2-4)$ & $7(6-8)$ & $<0.001$ \\
\hline
\end{tabular}

Abbreviations: BMI, body mass index; VFA, visceral fat area; MVPA, moderate-vigorous physical activity; PSQI, the Pittsburgh Sleep Quality Index. Data are shown as median (IQR) or percentage. Mann-Whitney U tests were used for continuous variables, and Fisher's exact tests were used for categorical variables. ${ }^{1}$ Sedentary time was expressed as the estimated hours of sedentary time per day, given as standardised $16 \mathrm{~h}$ of accelerometer wear time.

Figure 1 shows the proportion of PSQI $\geq 6$ according to sedentary time tertiles. There was a significant association between sedentary time and PSQI $\geq 6(p<0.001)$; the proportion of PSQI $\geq 6$ in Tertile 1 was $10.0 \%$, Tertile 2 was $17.8 \%$, and Tertile 3 was $22.9 \%$.

Table 2 shows the correlation coefficients between sedentary time and the seven PSQI component scores. After the Holm adjustment, higher sedentary time was found to be significantly associated with worse sleep latency score $(r=0.11, p=0.003)$ and worse daytime dysfunction score $(r=0.13, p=0.021)$. The regression analyses (Table S1) indicated that daytime dysfunction was the most significantly associated component with sedentary time. 


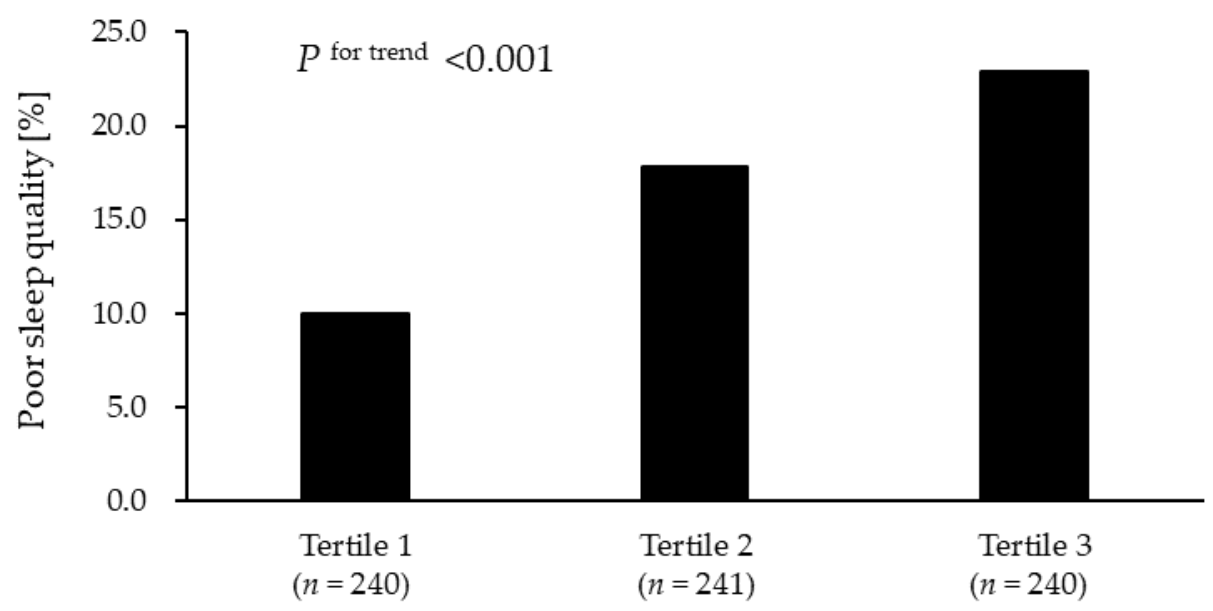

Sedentary time

Figure 1. Associations of sedentary time with poor sleep quality. The value shown is the proportion of poor sleep quality (PSQI $\geq 6$ ). Three groups according to the tertiles of sedentary time were assessed using Cochran-Armitage trend tests: Tertile 1, sedentary time $<10.4 \mathrm{~h}$; Tertile 2, $10.4 \mathrm{~h} \leq$ sedentary time $<11.5 \mathrm{~h}$; and Tertile 3 , sedentary time $\geq 11.5 \mathrm{~h}$.

Table 2. Correlation between sedentary time and the seven component scores of PSQI.

\begin{tabular}{|c|c|c|c|c|c|c|c|c|}
\hline & $\begin{array}{c}\text { PSQI } \\
\text { Global } \\
\text { Score }\end{array}$ & $\begin{array}{c}\text { Sleep } \\
\text { Quality }\end{array}$ & $\begin{array}{c}\text { Sleep } \\
\text { Latency }\end{array}$ & $\begin{array}{c}\text { Sleep } \\
\text { Duration }\end{array}$ & $\begin{array}{l}\text { Habitual } \\
\text { Sleep } \\
\text { Efficiency }\end{array}$ & $\begin{array}{l}\text { Sleep Dis- } \\
\text { turbance }\end{array}$ & $\begin{array}{c}\text { Use of } \\
\text { Sleeping } \\
\text { Medication }\end{array}$ & $\begin{array}{c}\text { Daytime } \\
\text { Dysfunction }\end{array}$ \\
\hline $\begin{array}{l}\text { Sedentary } \\
\text { time }\end{array}$ & $0.10^{*}$ & 0.06 & 0.11 * & -0.01 & 0.03 & 0.04 & 0.06 & $0.13^{* *}$ \\
\hline
\end{tabular}

Values show Spearman's correlation coefficients between sedentary time and PSQI global and seven component scores. ${ }^{*}$ Holm adjusted $p<0.05,{ }^{* *}$ Holm adjusted $p<0.01$.

Table 3 shows the OR $(95 \%$ CI) for PSQI $\geq 6$ according to the tertiles of sedentary time. After adjustment for several covariates (Model 2), there was a significant association between sedentary time and PSQI $\geq 6$ (P for trend $<0.001$ ); compared with Tertile 1, Tertile 2 and Tertile 3 had significantly higher ORs for PSQI $\geq 6$ (Tertile 2: OR $=2.07$ [95\% CI 1.15, 3.75]; Tertile 3: OR = 2.98 [95\% CI 1.62, 5.48]).

Table 3. Odds ratio of PSQI $\geq 6$ according to tertiles of sedentary time.

\begin{tabular}{ccccc}
\hline & \multicolumn{3}{c}{ Tertiles of Sedentary Time } & \\
\cline { 2 - 4 } & Tertile 1 $(n=$ & Tertile 2 $(n=$ & Tertile 3 $(\boldsymbol{n}=$ & $\boldsymbol{p}$-Value for \\
& $\mathbf{2 4 0})$ & $\mathbf{2 4 1 )}$ & $\mathbf{2 4 0 )}$ & Trend \\
\hline Model 1 & 1.00 (reference) & $1.87(1.09,3.20)$ & $2.44(1.44,4.14)$ & $<0.001$ \\
Model 2 & 1.00 (reference) & $2.07(1.15,3.75)$ & $2.98(1.62,5.48)$ & $<0.001$ \\
\hline
\end{tabular}

Values shown are odds ratios (95\% confidence intervals). Logistic regression models were used in the present study. Model 1 was adjusted for age and sex. Model 2 was adjusted for Model 1 plus smoking status, alcohol intake, CES-D score, and MVPA. Tertile 1, sedentary time $<10.4 \mathrm{~h}$; Tertile 2, $10.4 \mathrm{~h} \leq$ sedentary time $<11.5 \mathrm{~h}$; Tertile 3, sedentary time $\geq 11.5 \mathrm{~h}$.

Table S2 shows the association between PSQI $\geq 6$ and VFA and BMI, respectively. After adjustment for several covariates, there was a significant association between VFA (1SD) and PSQI $\geq 6$ (Model 2: OR $=1.31[95 \%$ CI 1.03, 1.67]). There were no significant associations between BMI (1SD) and PSQI $\geq 6$ (Model 2: OR $=1.21$ [95\% CI 0.98, 1.50]).

Figure 2 shows the results of the association between sedentary time and PSQI $\geq 6$ and further adjustment for VFA in Model 2. There was still a significant association between sedentary time and PSQI $\geq 6$ (P for trend $=0.001)$; compared with Tertile $1(<10.4 \mathrm{~h} /$ day), 
Tertile 2 and Tertile 3 had significantly higher ORs for PSQI $\geq 6$ (Tertile 2: OR = 2.06 [95\% CI 1.14,3,73]; Tertile 3: OR = 2.76 [95\% CI 1.49, 5.11]).

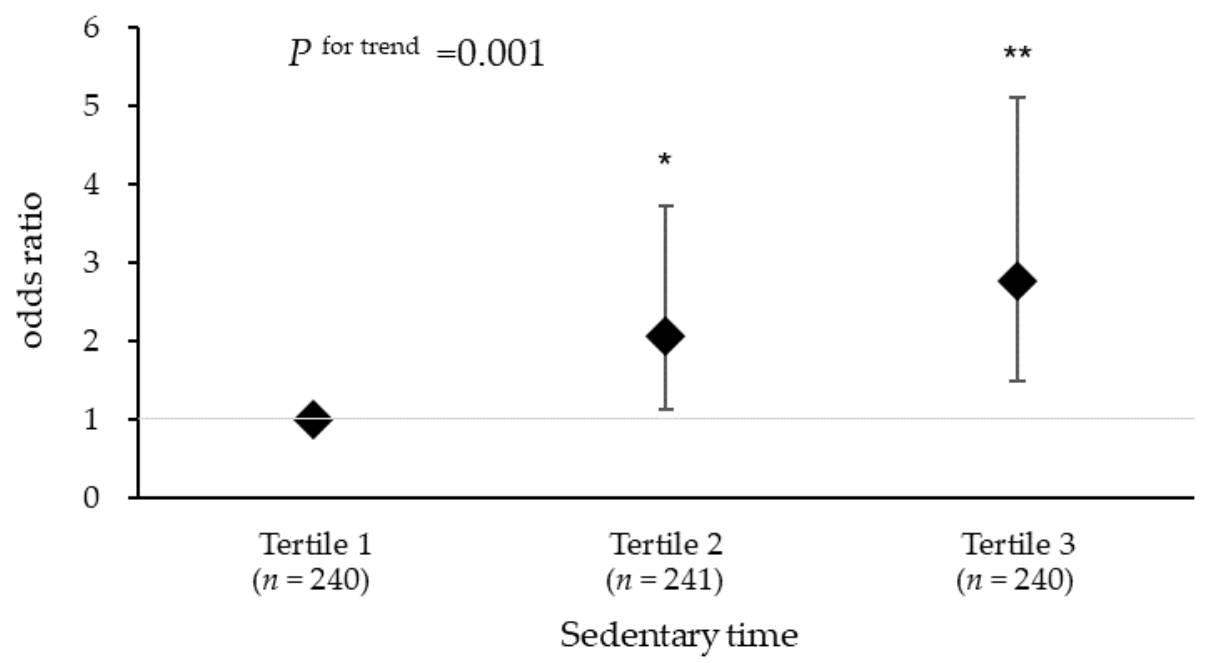

Figure 2. Odds ratio for the association between sedentary time and PSQI $\geq 6$. Data are presented as odds ratios and 95\% confidence intervals (error bar). Logistic regression models were used by adjusting for age, sex, smoking status, alcohol intake, CES-D score, MVPA, and VFA. Tertile 1, sedentary time $<10.4 \mathrm{~h}$; Tertile $2,10.4 \mathrm{~h} \leq$ sedentary time $<11.5 \mathrm{~h}$; Tertile 3 , sedentary time $\geq$ 11.5 h. ${ }^{*} p<0.05 ; * * 0.01$.

\section{Discussion}

To the best of our knowledge, this is the first study to investigate the association between objectively measured sedentary time and SQ while considering the association of visceral fat. Recent studies have reported that prolonged sedentary time and poor SQ were significantly associated with higher visceral fat $[30,31]$, indicating that the association between sedentary time and SQ may be partially influenced by visceral fat. We found that a higher sedentary time was independently associated with poorer SQ after adjustment for VFA. These results suggest that reducing sedentary time itself might contribute to better SQ.

We assessed sedentary behaviour, as well as MVPA, using an objective method, and a significant association was found between sedentary time and SQ even after adjustment for MVPA. A number of studies have examined the association between physical activity and sleep outcomes. Recent WHO guidelines recommended regular physical activity to improve sleep outcomes, such as SQ, and provided evidence for the association between sedentary behaviour and sleep outcomes; however, it was mainly focused on children and adolescents, especially for the association between sedentary time and sleep duration [7]. Although several studies have examined the association between sedentary behaviour and SQ in adults, the results have been inconsistent [8-11]. This is partly attributed to the differences in methodology used to measure sedentary behaviour among the studies.

In contrast to our results, Sloan et al. reported that there was no independent association between objectively measured sedentary time and SQ in adults in Singapore [11]. This can be partly explained by the differences of the study population in sedentary time. The Japanese population spends more time in sedentary behaviour compared to the populations of other countries [12]. The sedentary time duration in the present study was approximately 10.9 h/day, whereas in Sloan's study, it was 7.86 h/day. Although betweenstudy comparisons of physical activity levels are impeded by methodological differences in accelerometer measurement, the association of sedentary time with SQ might differ by countries depending on the differences in the amount of time spent on engaging in sedentary behaviour. The longer sedentary time in Japanese enabled us to consider the effect of much longer sedentary time on the SQ, which was not considered in Sloan's study. 
In our study, we found significant correlations between sedentary time and two components of PSQI: latency and daytime dysfunction. The physiological mechanisms between sedentary behaviour and SQ are not well understood, and previous studies have suggested a potential mechanism between exercise and SQ. Exercise can decrease sleep latency and increase slow-wave sleep [32,33], which may partially explain the association between sedentary time and sleep latency. As for daytime dysfunction, a bidirectional association might be considered. Some studies reported that poor SQ was associated with low scores on the Short Form-36 questionnaire, which assessed the quantity and quality of daily physical activity $[5,34]$. Further studies are needed to reveal how sedentary behaviour affects SQ, independent of physical activity.

Previous studies have reported that obesity and metabolic disorders are associated with poor SQ $[35,36]$. Although BMI is frequently used in clinical settings to assess obesity status (general obesity), recent studies have shown that VFA (index of abdominal obesity) is more strongly associated with hypertension, type 2 diabetes, dyslipidaemia, and cardiovascular disease than BMI [37-39]. In addition, VFA is more strongly associated with sleep disturbance than BMI [16]. We found that VFA was significantly associated with SQ, whereas BMI was not, which may be attributed to the aforementioned difference between VFA and BMI. However, Dekker et al. reported that VFA was significantly higher in individuals with poor $\mathrm{SQ}$, but the association was attenuated after adjustment for total body fat [40]. This is partly explained by the fact that Asian individuals have a higher susceptibility to metabolic syndrome, with visceral fat accumulation even in individuals with a lower BMI, compared with Western individuals [15]. In addition to reducing sedentary behaviour, a population-specific approach for coping with obesity may be required for better SQ. Conversely, another possible explanation could be that poor SQ can be linked to increasing risk for obesity via hormonal regulations, such as leptin [31]. Thus, further longitudinal studies are needed for elucidating the direction of these associations.

We found a significant linear association between longer sedentary time and poor SQ. As an individual's activity time in a given day is finite, reducing sedentary time leads to an increase in other physical activities. Although physical activity is reported to be good for health, recent reviews have suggested that higher levels of occupational physical activity are associated with an increased risk of poor SQ [41]. Therefore, it is necessary to not only reduce sedentary time but also consider how to increase other physical activities. To achieve good SQ, non-occupational activities such as exercise, walking, and activities of daily living would be beneficial for reducing sedentary time.

The strengths of this study include measurement of VFA using an abdominal bioimpedance method, and objective measurement of sedentary time and physical activity using an accelerometer. However, this study had some limitations. First, the cross-sectional design of our study could not establish a causal relationship between sedentary behaviour and SQ. Edwards et al. reported that an experimental increase in sedentary behaviour decreased SQ, which supports our causal hypothesis [42]. Second, the loss of participants due to insufficient accelerometer data could have led to selection bias. Third, there might have been an overestimation of the sedentary time, since sedentary behaviour was defined based on intensity levels ( $\leq 1.5 \mathrm{METs})$ using an accelerometer which cannot distinguish between sitting and standing postures. Fourth, although we adjusted for several covariates, there might have been residual confounding variables. The wide age range in this study may bias the results of the association between sedentary behaviour and SQ. Finally, as this study was confined to participants from a particular country, region, race, and limited sample size, reproducibility should be confirmed by the inclusion of a large number of participants from different regions and/or races.

\section{Conclusions}

Objectively measured sedentary time was significantly associated with poor SQ, especially for daytime dysfunction. Furthermore, although VFA was significantly associated with poor SQ, higher sedentary time was independently associated with poor SQ after 
adjustment for VFA. Reducing sedentary time itself might help to improve the SQ of people with high sedentarism. Further longitudinal or interventional studies are required to confirm the effectiveness of reducing sedentary time on SQ.

Supplementary Materials: The following is available online at https://www.mdpi.com/article/10 .3390/ijerph19053145/s1, Table S1: Association between the seven component scores of PSQI and sedentary time. Table S2: Association between PSQI $\geq 6$ and VFA and BMI, respectively.

Author Contributions: Conceptualization, K.K.; methodology, K.K., Y.Y., M.S. and K.M. (Kenta Mori); formal analysis, K.K., T.Y. (Tohru Yamaguchi) and K.I.; investigation, K.K., N.O., T.Y. (Tohru Yamaguchi), Y.Y., M.S., K.M. (Kenta Mori), Y.K., T.Y.( Takuji Yasukawa), K.M. (Koichi Murashita), S.N and K.I.; data curation, T.Y. (Tohru Yamaguchi), Y.Y. and M.S.; writing-original draft preparation, K.K.; writing—review and editing, N.O., T.Y. (Tohru Yamaguchi), S.N. and K.I; visualization, K.K.; supervision, Y.K., S.N. and K.I.; project administration, Y.K., S.N. and K.I.; funding acquisition, Y.K., T.Y.(Takuji Yasukawa), K.M. (Koichi Murashita), S.N. and K.I. All authors have read and agreed to the published version of the manuscript.

Funding: This work was supported by JST COI Grant Number JPMJCE1302, and Kao Corporation (Tokyo, Japan).

Institutional Review Board Statement: This study was conducted according to the guidelines of the Declaration of Helsinki, and approved by the Ethics Committee of Hirosaki University School of Medicine (2018-012, 2018-063).

Informed Consent Statement: Informed consent was obtained from all subjects involved in the study.

Data Availability Statement: The data presented in this study are available on request from the Hirosaki University COI Program Institutional Data Access/Ethics Committee (contact via e-mail: coi@hirosaki-u.ac.jp) for researchers who meet the criteria for access to the data. Researchers must be approved by the research ethics review board at the organisations of their affiliations. The data cannot be shared publicly because of ethical concerns.

Acknowledgments: The authors acknowledge all the participants for their cooperation in the Iwaki Health Promotion Project and the entire staff of the project.

Conflicts of Interest: The authors K.K, N.O., T.Y. (Tohru Yamaguchi), M.S., Y.Y., K.M. (Kenta Mori) and Y.K. were employed by Kao Corporation. All other authors declare no competing interests.

\section{References}

1. Koyanagi, A.; Stickley, A. The Association between Sleep Problems and Psychotic Symptoms in the General Population: A Global Perspective. Sleep 2015, 38, 1875-1885. [CrossRef] [PubMed]

2. Leger, D.; Poursain, B.; Neubauer, D.; Uchiyama, M. An international survey of sleeping problems in the general population. Curr. Med. Res. Opin. 2008, 24, 307-317. [CrossRef] [PubMed]

3. Stranges, S.; Tigbe, W.; Gómez-Olivé, F.X.; Thorogood, M.; Kandala, N.B. Sleep Problems: An Emerging Global Epidemic? Findings From the INDEPTH WHO-SAGE Study Among More Than 40,000 Older Adults From 8 Countries across Africa and Asia. Sleep 2012, 35, 1173-1181. [CrossRef] [PubMed]

4. Buysse, D.J. Sleep Health: Can We Define It? Does It Matter? Sleep 2014, 37, 9-17. [CrossRef] [PubMed]

5. Kido, K.; Hatakeyama, S.; Imai, A.; Yamamoto, H.; Tobisawa, Y.; Yoneyama, T.; Yoneyama, T.; Hashimoto, Y.; Koie, T.; Nakaji, S.; et al. Sleep Disturbance Has a Higher Impact on General and Mental Quality of Life Reduction than Nocturia: Results from the Community Health Survey in Japan. Eur. Urol. Focus. 2019, 5, 1120-1126. [CrossRef]

6. Physical Activity Guidelines Advisory Committee, U.S. Department of Health and Human Services. Physical Activity Guidelines Advisory Committee Scientific Report; Physical Activity Guidelines Advisory Committee, U.S. Department of Health and Human Services: Washington, DC, USA, 2018.

7. World Health Organization. WHO Guidelines for Physical Activity and Sedentary Behaviour; WHO: Geneva, Switzerland, 2020.

8. Yang, Y.; Shin, J.C.; Li, D.; An, R. Sedentary Behavior and Sleep Problems: A Systematic Review and Meta-Analysis. Int. J. Behav. Med. 2017, 24, 481-492. [CrossRef]

9. Creasy, S.A.; Crane, T.E.; Garcia, D.O.; Thomson, C.A.; Kohler, L.N.; Wertheim, B.C.; Baker, L.D.; Coday, M.; Hale, L.; Womack, C.R.; et al. Higher Amounts of Sedentary Time are Associated with Short Sleep Duration and Poor Sleep Quality in Postmenopausal Women. Sleep 2019, 42, zsz093. [CrossRef]

10. Park, H.; Suh, B. Association Between Sleep Quality and Physical Activity According to Gender and Shift Work. J. Sleep Res. 2020, 29, e12924. [CrossRef] 
11. Sloan, R.A.; Kim, Y.; Sawada, S.S.; Asakawa, A.; Blair, S.N.; Finkelstein, E.A. Is Less Sedentary Behavior, More Physical Activity, or Higher Fitness Associated with Sleep Quality? A Cross-Sectional Study in Singapore. Int. J. Environ. Res. Public Health. 2020, 17, 1337. [CrossRef]

12. Bauman, A.; Ainsworth, B.E.; Sallis, J.F.; Hagströmer, M.; Craig, C.L.; Bull, F.C.; Pratt, M.; Venugopal, K.; Chau, J.; Sjöström, M. IPS Group. The Descriptive Epidemiology of Sitting. Am. J. Prev. Med. 2011, 41, 228-235. [CrossRef]

13. Migueles, J.H.; Cadenas-Sanchez, C.; Ekelund, U.; Delisle Nyström, C.; Mora-Gonzalez, J.; Löf, M.; Labayen, I.; Ruiz, J.R.; Ortega, F.B. Accelerometer Data Collection and Processing Criteria to Assess Physical Activity and Other Outcomes: A Systematic Review and Practical Considerations. Sports Med. 2017, 47, 1821-1845. [CrossRef] [PubMed]

14. Rodrigues, G.D.; Fiorelli, E.M.; Furlan, L.; Montano, N.; Tobaldini, E. Obesity and Sleep Disturbances: The "Chicken or the Egg" Question. Eur. J. Intern. Med. 2021, 92, 11-16. [CrossRef] [PubMed]

15. Nishizawa, H.; Shimomura, I. Population Approaches Targeting Metabolic Syndrome Focusing on Japanese Trials. Nutrients 2019, 11, 1430. [CrossRef] [PubMed]

16. Shinohara, E.; Kihara, S.; Yamashita, S.; Yamane, M.; Nishida, M.; Arai, T.; Kotani, K.; Nakamura, T.; Takemura, K.; Matsuzawa, Y. Visceral Fat Accumulation as an Important Risk Factor for Obstructive Sleep Apnoea Syndrome in Obese Subjects. J. Intern. Med. 1997, 241, 11-18. [CrossRef]

17. Nakaji, S.; Ihara, K.; Sawada, K.; Parodi, S.; Umeda, T.; Takahashi, I.; Murashita, K.; Kurauchi, S.; Tokuda, I. Social Innovation for Life Expectancy Extension Utilizing a Platform-centered System Used in the Iwaki Health Promotion Project: A Protocol Paper. SAGE Open Med 2021, 9, 205031212110026. [CrossRef]

18. Jung, S.; Lee, S.; Lee, S.; Bae, S.; Imaoka, M.; Harada, K.; Shimada, H. Relationship between Physical Activity Levels and Depressive Symptoms in Community-Dwelling Older Japanese Adults. Geriatr. Gerontol. Int. 2018, 18, 421-427. [CrossRef]

19. Harada, K.; Lee, S.; Lee, S.; Bae, S.; Anan, Y.; Harada, K.; Shimada, H. Distance from Public Transportation and Physical Activity in Japanese Older Adults: The Moderating Role of Driving Status. Health Psychol. 2018, 37, 355-363. [CrossRef]

20. Jung, S.; Lee, S.; Bae, S.; Lee, S.; Makino, K.; Shinkai, Y.; Shimada, H. Effectiveness of the KENKOJISEICHI Local Revitalization System on Cognitive Function Change in Older Adults with Mild Cognitive Impairment: Study Protocol for a Randomized Controlled Trial. Trials 2018, 19, 276. [CrossRef]

21. Doi, Y.; Minowa, M.; Uchiyama, M.; Okawa, M.; Kim, K.; Shibui, K.; Kamei, Y. Psychometric Assessment of Subjective Sleep Quality Using the Japanese Version of the Pittsburgh Sleep Quality Index (PSQI-J) in Psychiatric Disordered and Control Subjects. Psychiatry Res. 2000, 97, 165-172. [CrossRef]

22. Yamaguchi, T.; Ozato, N.; Katashima, M.; Sawada, K.; Katsuragi, Y.; Ihara, K.; Nakaji, S. A Novel Method to Visualize the Dietary Macronutrient Composition of Smaller Visceral Fat Accumulation. Front. Nutr. 2020, 6, 194. [CrossRef]

23. Ryo, M.; Maeda, K.; Onda, T.; Katashima, M.; Okumiya, A.; Nishida, M.; Yamaguchi, T.; Funahashi, T.; Matsuzawa, Y.; Nakamura, T.; et al. A New Simple Method for the Measurement of Visceral Fat Accumulation by Bioelectrical Impedance. Diabetes Care 2005, 28, 451-453. [CrossRef] [PubMed]

24. Kobayashi, S.; Murakami, K.; Sasaki, S.; Okubo, H.; Hirota, N.; Notsu, A.; Fukui, M.; Date, C. Comparison of Relative Validity of Food Group Intakes Estimated by Comprehensive and Brief-type Self-administered Diet History Questionnaires Against $16 \mathrm{~d}$ Dietary Records in Japanese Adults. Public Health Nutr. 2011, 14, 1200-1211. [CrossRef] [PubMed]

25. Kobayashi, S.; Honda, S.; Murakami, K.; Sasaki, S.; Okubo, H.; Hirota, N.; Notsu, A.; Fukui, M.; Date, C. Both Comprehensive and Brief Self-Administered Diet History Questionnaires Satisfactorily Rank Nutrient Intakes in Japanese Adults. J. Epidemiol. 2012, 22, 151-159. [CrossRef] [PubMed]

26. Radloff, L.S. The CES-D Scale: A Self-Report Depression Scale for Research in the General Population. Appl. Psychol. Meas. 1977, 1, 385-401. [CrossRef]

27. Qi, Q.; Strizich, G.; Merchant, G.; Sotres-Alvarez, D.; Buelna, C.; Castaneda, S.F.; Gallo, L.C.; Cai, J.; Gellman, M.D.; Isasi, C.R.; et al. Objectively Measured Sedentary Time and Cardiometabolic Biomarkers in US Hispanic/Latino Adults: The Hispanic Community Health Study/Study of Latinos (HCHS/SOL). Circulation 2015, 132, 1560-1569. [CrossRef] [PubMed]

28. Diaz, K.M.; Howard, V.J.; Hutto, B.; Colabianchi, N.; Vena, J.E.; Safford, M.M.; Blair, S.N.; Hooker, S.P. Patterns of Sedentary Behavior and Mortality in U.S. Middle-Aged and Older Adults: A National Cohort Study. Ann. Intern. Med. 2017, 167, 465-475. [CrossRef] [PubMed]

29. Gilchrist, S.C.; Howard, V.J.; Akinyemiju, T.; Judd, S.E.; Cushman, M.; Hooker, S.P.; Diaz, K.M. Association of Sedentary Behavior With Cancer Mortality in Middle-aged and Older US Adults. JAMA Oncol 2020, 6, 1210-1217. [CrossRef]

30. Ando, S.; Koyama, T.; Kuriyama, N.; Ozaki, E.; Uehara, R. The Association of Daily Physical Activity Behaviors with Visceral Fat. Obes. Res. Clin. Pract. 2020, 14, 531-535. [CrossRef]

31. Sweatt, S.K.; Gower, B.A.; Chieh, A.Y.; Liu, Y.; Li, L. Sleep Quality is Differentially Related to Adiposity in Adults. Psychoneuroendocrinology. 2018, 98, 46-51. [CrossRef]

32. Kubitz, K.A.; Landers, D.M.; Petruzzello, S.J.; Han, M. The Effects of Acute and Chronic Exercise on Sleep. Sports Med. 1996, 21, 277-291. [CrossRef]

33. Driver, H.S.; Taylor, S.R. Exercise and Sleep. Sleep Med. Rev. 2000, 4, 387-402. [CrossRef] [PubMed]

34. Sasai, T.; Inoue, Y.; Komada, Y.; Nomura, T.; Matsuura, M.; Matsushima, E. Effects of Insomnia and Sleep Medication on Health-related Quality of Life. Sleep Med. 2010, 11, 452-457. [CrossRef] [PubMed] 
35. Algul, A.; Ates, M.A.; Semiz, U.B.; Basoglu, C.; Ebrinc, S.; Gecici, O.; Gulsun, M.; Kardesoglu, E.; Cetin, M. Evaluation of General Psychopathology, Subjective Sleep Quality, and Health-related Quality of Life in Patients with Obesity. Int. J. Psychiatry Med. 2009, 39, 297-312. [CrossRef] [PubMed]

36. Koren, D.; Dumin, M.; Gozal, D. Role of Sleep Quality in the Metabolic Syndrome. Diabetes Metab. Syndr. Obes. 2016, 9, 281-310. [CrossRef]

37. Després, J.P. Body Fat Distribution and Risk of Cardiovascular Disease. Circulation 2012, 126, 1301-1313. [CrossRef]

38. Matsushita, Y.; Nakagawa, T.; Yamamoto, S.; Takahashi, Y.; Yokoyama, T.; Noda, M.; Mizoue, T. Associations of Visceral and Subcutaneous Fat Areas With the Prevalence of Metabolic Risk Factor Clustering in 6292 Japanese Individuals: The Hitachi Health Study. Diabetes Care 2010, 33, 2117-2119. [CrossRef]

39. Shah, R.V.; Murthy, V.L.; Abbasi, S.A.; Blankstein, R.; Kwong, R.Y.; Goldfine, A.B.; Jerosch-Herold, M.; Lima, J.A.; Ding, J.; Allison, M.A. Visceral Adiposity and the Risk of Metabolic Syndrome Across Body Mass Index: The MESA Study. JACC Cardiovasc. Imaging 2014, 7, 1221-1235. [CrossRef]

40. Dekker, S.A.; Noordam, R.; Biermasz, N.R.; De Roos, A.; Lamb, H.J.; Rosendaal, F.R.; Rensen, P.C.N.; Van Heemst, D.; De Mutsert, R. Habitual Sleep Measures are Associated with Overall Body Fat, and not Specifically with Visceral Fat, in Men and Women. Obesity 2018, 26, 1651-1658. [CrossRef]

41. Cillekens, B.; Lang, M.; Van Mechelen, W.; Verhagen, E.; Huysmans, M.A.; Holtermann, A.; Van der Beek, A.J.; Coenen, P. How Does Occupational Physical Activity Influence Health? An Umbrella Review of 23 Health Outcomes Across 158 Observational Studies. Br. J. Sports Med. 2020, 54, 1474-1481. [CrossRef]

42. Edwards, M.K.; Loprinzi, P.D. Experimentally Increasing Sedentary Behavior Results in Decreased Sleep Quality Among Young Adults. Ment. Health Phys. Act. 2017, 12, 132-140. [CrossRef] 